\title{
Medicine and Law in the Times of COVID-19 Pandemic: Understanding the Interphase
}

\author{
Arun Kumar ${ }^{1}$, Munish Kapila², Ritu Pankaj ${ }^{3}$
}

\begin{abstract}
COVID-19 has heralded a wide set of challenges involving not only the medical management of the patients but also the legal dilemma with regards to provision of healthcare services. The medical professionals have experienced difficulty in balancing their obligations and duties toward the patients, and their own right to safeguard self, family, and their clinical establishments. The professional regulatory bodies and government have formulated new policies and amended laws to control the current situation. It is the need of the hour to be mindful of the existing laws and our rights and duties in the era of current pandemic. Collaborative efforts are needed to provide best possible care in the current unpredictable environment. The commonly encountered problems and their possible solutions are discussed in the context of medicolegal framework applicable to Indian medical practitioner.

Keywords: COVID-19, Legal issues, Medical profession.

Indian Journal of Critical Care Medicine (2020): 10.5005/jp-journals-10071-23553
\end{abstract}

\section{INTRODUCTION}

The World Health Organization declared coronavirus disease (COVID-19), a pandemic on March 11, 2020. The contagion, since then has ushered arduous and perplexing times globally. The requisite responses, such as quarantining of entire communities and social isolation, have abruptly changed daily life. ${ }^{1}$

The healthcare facilities too, grappled with constraints to restructure their existing edifices into COVID zones. The major concerns have been preventing the spread of infections, with focus on personal protective equipment (PPE), modifying policies and workflows regarding management of suspects and confirmed cases, bolstering intensive care services, and providing emotional and psychological support to healthcare workers. ${ }^{2}$

The situation pushed the medical professionals on a sticky wicket, necessitating changes in the clinical practice.

The professional bodies did expedite their efforts to identify the challenges, and modified the existing guidelines, to promote safety of healthcare providers and society in general. The Central and the State government also took note of the situation and formulated policies and amended the existing laws.

While this pandemic is far from over and is here to stay, it is essential that the medical community stays cognizant not only about the clinical management but also about the legal aspects intertwined with it. We all need to be mindful about the existing laws and our rights and duties in the era of current pandemic.

\section{Legal Framework}

A medical professional, by virtue of the powers vested to him because of skills, knowledge, and training, is obliged to follow ethical code of conduct.

There are certain additional statutes, which have been notified in the current pandemic and regulate the conduct and practice of medical professionals. Those relevant in the current context, along with the rights and safeguards are discussed below.

\footnotetext{
${ }^{1}$ Department of Intensive Care, Medical Intensive Care Unit, Fortis Healthcare Ltd, Mohali, Punjab, India

${ }^{2}$ Advocate, Punjab \& Haryana High Court, Chandigarh, India

${ }^{3}$ Department of Lab Medicine, Fortis Healthcare Ltd, Mohali, Punjab,
} India

Corresponding Author: Arun Kumar, Department of Intensive Care, Medical Intensive Care Unit, Fortis Healthcare Ltd, Mohali, Punjab, India, Phone: +91 9872828779, e-mail: arun.udhv@gmail.com

How to cite this article: Kumar A, Kapila M, Pankaj R. Medicine and Law in the Times of COVID-19 Pandemic: Understanding the Interphase. Indian J Crit Care Med 2020;24(10):971-974.

Source of support: Nil

Conflict of interest: None

\section{Indian Medical Council (Professional Conduct, Etiquette, and Ethics) Regulations, 2002 ${ }^{3}$}

Section 2.1.1 of Indian Medical Council Regulation 2002, details the duties of physician to their patients and obligations to sick. It clearly defines that no physician shall arbitrarily refuse treatment to a patient.

Section 2.1.2 of the above regulations ascertains that, a medical practitioner having any incapacity detrimental to the patient or which can affect his performance vis-à-vis the patient is not permitted to practice his profession.

In addition, section 5.2 of the above regulations has a note on public and community health. The subsection reads:

The physicians, especially those engaged in public health work, should enlighten the public concerning quarantine regulations and measures for the prevention of epidemic and communicable diseases. At all times the physician should notify the constituted public health authorities of every case of communicable disease

() The Author(s). 2020 Open Access This article is distributed under the terms of the Creative Commons Attribution 4.0 International License (https://creativecommons. org/licenses/by-nc/4.0/), which permits unrestricted use, distribution, and non-commercial reproduction in any medium, provided you give appropriate credit to the original author(s) and the source, provide a link to the Creative Commons license, and indicate if changes were made. The Creative Commons Public Domain Dedication waiver (http://creativecommons.org/publicdomain/zero/1.0/) applies to the data made available in this article, unless otherwise stated. 
under his care, in accordance with the laws, rules and regulations of the health authorities.

The section thus elaborates that "whenever an epidemic occurs, a physician should not abandon his duty for the fear of contacting the disease". The only exception will be a situation where the physician himself has a medical condition, which places him in a very high-risk category upon exposure to contagion. The responsible physician is expected to create awareness about the disease in the society and work in accordance with the framework of established rules and regulations.

\section{The Epidemic Diseases Act, 1897}

The Epidemic diseases act, 1897 (the ED Act), ${ }^{4}$ was invoked by the Indian Government on March 11, 2020, empowering both the Central and the State government(s) to take actions to prevent spread of such diseases. ${ }^{5}$ The provisions of this act are now applicable to medical professionals and general public, and this includes the patients.

The first three sections of the act elaborate measures to prevent and contain the spread of an infectious disease and pronounce the punishment for disobeying the government orders given under this act.

The section 4 of this act, is exclusively applicable to the healthcare professionals, and provides legal protection to every person who does any action, in good faith. This section provides immunity from legal action for any healthcare worker acting under the provisions of the act.

\section{The Indian Penal Code, 1860}

The Indian penal code, $1860,{ }^{6}$ under section $188,269,270$, prescribes penance (punishment/fine or both) for any person who is found to be negligently (unintentionally) or malignantly (intentionally) contributing to spread of an infectious disease.

Thus, reporting of a suspected or diagnosed COVID case, to the health authorities is mandatory as per the provisions of this law to prevent community spread. $^{7}$

\section{The Disaster Management Act, 2005}

The legislative intent of the Disaster Management act 2005 (the DM Act $)^{8}$ is to, "provide for the effective management of disasters". The current lockdown was imposed under Section 6 (2) (i) of the act, as per the provisions of the concurrent list of the Constitution of India.

Under section 65 of this act, the government has the power of requisition of resources with any authority or person and their services also. The expenses and logistics of such services are borne by the authorities requisitioning the services.

The Government can thus acquire a public or a private healthcare facility and convert it into a COVID treatment zone.

\section{Rights and Safeguards}

The Constitution of India, in its Part III, guarantees that every individual is entitled to enjoy certain basic rights known as fundamental rights. ${ }^{9}$ These fundamental rights are statutory, and an individual can file a writ petition or public interest litigation in the Supreme Court (under Art. 32-Right to Constitutional Remedies) or the High Court, if there is any encroachment of these rights. The only provision, where Fundamental Rights can be curtailed is a state of national emergency caused by war, external aggression, or armed rebellion.

Article 21, of the Constitution of India, guarantees "protection of life and personal liberty". The article prohibits the deprivation of the above rights except according to the procedure established by the court of law, and cannot be suspended even during the pandemic. ${ }^{10}$

The article 21, thus provides ample protection to healthcare providers to move the higher judiciary if they are forced to work under suboptimal conditions. ${ }^{11}$

The recent promulgation of an ordinance to amend the ED Act, ${ }^{12}$ is a step to provide protection to the healthcare services personnel and their property from an act of violence during an epidemic. The ordinance declares such acts of violence, cognizable, and nonbailable offences and defines penalties for the same.

\section{Surviving the Pandemic}

There may be an unending list of questionnaire from the ethical and legal point of view and some of these may be well beyond the scope of this article. The commonly encountered scenarios and their possible solutions are discussed.

\section{Can a Doctor Refuse Treatment of COVID-19 Patient?}

A medical practitioner, who is qualified and has the basic infrastructure to treat a COVID-19 patient, should not refuse, unless his own health issues prevent him from doing so. This is in concordance with section 2.1 of the Indian Medical Council Regulations 2002. ${ }^{3}$ However, in the best interests of the patient, the doctor can refer him/her to a higher center if necessary, but only after providing the first aid and ensuring safe transfer.

Refusal to treat a COVID patient for any other reason will amount to contravention of Regulation 5.2 of the Indian Medical Council Regulations 2002, which states precisely, that a physician should not abandon his duty during an epidemic, for the fear of contracting the disease. ${ }^{3}$

Implicit/explicit refusal to treat, will amount to infringement of Article 21 of the Constitution of India. ${ }^{10}$

\section{Would Failure to Adhere to Government Guidelines be Treated as Negligence?}

It is of utmost pertinence to stay abreast with the latest government guidelines and regional polices, and follow them judiciously. The medical practitioner and the administration is duty bound to be prepared to deal with all eventualities arising from admitting or treating a COVID suspect or a positive patient. The admission or treatment should only be performed if the hospital is authorized to treat COVID.

Failure to adhere to the guidelines would sure invite the wrath of the government bodies and adverse legal consequences.

\section{Can a Private Practitioner be Forced to Open his Establishment?}

It must be understood that, as per Article 19 (1) (g), ${ }^{13}$ every citizen of India has the right to practice any profession subject to Articles 19 (6) (g) (i), which prescribes the necessary professional and technical qualifications.

It may be argued that, if a person has a right to practice any profession, he has right to stop practicing it as well. However, the same shall have limited applicability in the case of medical professionals.

Medical service is an essential service, and a physician is expected to contribute every bit when the nation is dealing with an exigency taking the all-necessary precautions. As stated above, under section 65, of the DM act 2005, the government has the power of requisition of resources with any authority or person and their services also. ${ }^{8,14}$ 


\section{Can a Medical Professional Refuse to Treat, if there is not Enough PPE Kits or Masks?}

A medical professional is well within his right to ask for PPE kits and mask as non-availability of these may expose him to the contagion. However in a pandemic, he/she cannot refuse to discharge his duty simply from the fear of contracting the disease. A physician is thus expected to improvise by whatever means to safeguard his own health and ensure continuation of care in the best interest of the patient. The hospital administrators should take efforts to reduce the risk to healthcare professionals to the greatest extent possible.

The medical institutes should ensure availability of PPE to their frontline staff, especially those working in triage and dealing with COVID suspects and positive patients.

\section{Can a Government Ask a Physician to go Beyond the Scope of his Degree to Attend to a Patient?}

Section 7.21 of the IMC regulation 2002 establishes that "A physician shall not claim to be a specialist unless he has a special qualification in that branch". ${ }^{3}$ It is hence the duty of a physician to not overstep his sphere of training and expertise and to limit their practice within the ambit of these qualifications. ${ }^{15}$

However, as per the section 5.2 (IMC regulations 2002), it is elaborated that "whenever an epidemic occurs, a physician should not abandon his duty for the fear of contacting the disease". ${ }^{3}$

The physicians thus, have a duty to work with in their core competence but may be expected to depart in order to care for patients in the circumstances of the peak of the epidemic.

The statuary bodies and government, however, need to assure the doctors that they will not be subjected to unreasonable criticism or face penalty, in context to difficult decisions they took or the standard of care provided by them during the pandemic.

\section{Can Resources be Allocated Preferentially to Patients with Better Likelihood of Survival?}

The Indian professional regulatory bodies have not formulated any specific guidelines about this sensitive topic. The American Medical Association (AMA) has addressed this pertinent issue. Guidelines and criteria have been rolled out for avoidance of life support interventions, especially advanced respiratory support, to those with extremely poor outcomes. The AMA code of ethics recommends, explanation of allocation policies to the patients who are denied access to limited resources and to the public, and consideration of stewardship in balancing the needs of individual patients and those of community at large. ${ }^{16}$

\section{What Additional Precautionary Measures Would Safeguard the Interests of the Medical Practitioner?}

COVID-19 pandemic heralds complex work environment situation, something that have not been experienced by most of us during our career. We need to religiously follow the guidelines released by the statutory bodies. The position statement, released by the Indian Society of Critical Care Medicine regarding management of critically ill patients ${ }^{17}$ and recent, Indian Council of Medical Research Consensus Guidelines on "Do Not Attempt Resuscitation"18 are valuable tools, which provide guidance on managing these complex clinical situations. The electronic media and webinars can be an effective tool to discuss intricate issues concerning the clinical management. The physicians should always seek professional advice and supervision from colleagues.

\section{Patient Segregation}

All hospitals (government and private) should have separate corners for screening of suspected cases of COVID-19. It is mandatory to record the travel history of the patients including the history of contact with a suspected or confirmed case of COVID-19.

\section{Record Keeping and Data Sharing}

The healthcare facilities need to ensure that the information regarding all suspect and positive cases be provided to state integrated disease surveillance unit and the local administration at the earliest. Always keep a record of thermal check and screening protocols for employees and any person entering the hospital. This would be a savior against a mala fide complaint for transmission of infection.

Prepare, relevant institution specific standard operating procedure (SOP) documents, based on the available government and regulatory body guidelines.

\section{Telemedicine}

Telemedicine is being propagated and progressively adopted to prevent transmission risk to both healthcare providers and patients. A detailed guideline has been issued by the Board of Governors in consultation with NITI Aayog and has been an amendment of Indian Medical Council (PCEE) regulations 2002. These guidelines are an attempt to provide a standardized regulatory and legal framework for telemedicine in India. ${ }^{19}$ It does make sense to be thorough with these amendments to stay on the safe side of the law. A mandatory online course within 3 years of the current notification is recommended.

\section{Informed Consent-Newer Scopes}

There is no denying the fact that a prior informed consent is one of the fundamental components of safe medical practice. Insufficient information or an invalid consent is one of the easiest grounds to prove medical negligence, which is difficult to defend. Certain newer scope for the type of consent and the process itself has been identified amid the current pandemic and lockdown situation.

These include

- Consent for declaring travel history and contact with any suspect.

- Consent for being treated in a COVID zone till the availability of report.

- General consent for procedures by telephonic conversation.

- Consent for evolving experimental and compassionate therapies.

A bigger challenge has been the process of obtaining the consent. The in-person consent may be difficult, due to the patient being kept in isolation, or the legally authorized representatives being constrained at home. In such case, the healthcare facility can arrange a three-way audio/video call with the patient/patient's representative and an impartial witness. The impartial witness and the proceduralist can provide a written attestation that the patient verbally agreed or denied. The consent form may also be provided to the family via social media platforms or email. The signed or a scanned copy, video recording of such communication should be placed in the medical records.

A detailed reference to this process has been elaborated on the web page of Vanderbilt University. ${ }^{20}$ 


\section{CONCLUSION}

The COVID-19 situation is a dynamic situation and evolving with regional variances. The pandemic is here to stay and many more may just be knocking at the door. We have definitely struggled, not because of the disease but the fear of unknown.

The Indian laws while imposing regulations on practice, does simultaneously provide provisions to safeguard the interest of the medical practitioner.

The professional governing bodies all over the world, including the AMA (Code of Medical Ethics Opinion 8.3) command professionals to have an obligation to provide urgent medical care during disasters. However, the code recognizes that physician workforce is a limited resource and should be utilized judiciously while maintaining a fine balance between the present day risks and need to provide care in the future.

The physicians have a moral duty to treat, but they do have the same human rights as all citizens and need to be protected against infectious diseases. The hospitals, professional regulatory bodies, and governments must ensure and provide the necessary resources, to protect the staff caring for the infected patients-not just PPE, but also training, environmental controls, and policies and procedures to prevent spread.

A balance of efficiency and innovation is a pressing priority. It is the need of the hour to be mindful of the existing laws and our rights and duties in the era of current pandemic.

\section{References}

1. Shanafelt T, Ripp J, Trockel M. Understanding and addressing sources of anxiety among health care professionals during the COVID-19 pandemic. JAMA 2020. DOI: 10.1001/jama.2020.5893.

2. Liew MF, Siow WT, MacLaren G, See KC. Preparing for COVID-19: early experience from an intensive care unit in Singapore. Crit Care 2020;24(1)::83. DOI: 10.1186/s13054-020-2814-x.

3. Indian Medical Council (professional conduct, etiquette and ethics) Regulations 2002. Issues Med Ethics 2002;10(3):66-70. Available from: https://www.mciindia.org/CMS/wp-content/uploads/2017/10/ Ethics-Regulations-2002.pdf.

4. Rakesh PS. The epidemic diseases act of 1897: public health relevance in the current scenario. Indian J Med Ethics 2016;1(3):156-160.

5. Mehta A, Srivastva K, Shah A, Epidemic Disease Act 1897-Dusting an Old Cloak [Internet]. 2020 Mar 31 [cited 2020 may 28] Available from: https://corporate.cyrilamarchandblogs.com/2020/03/epidemicdiseases-act-1897-dusting-an-old-cloak/.

6. THE INDIAN PENAL CODE, 1860.

7. Institute of Medicine and Law [Internet] MedLegal Advisory on COVID-19 Pandemic[updated 2020 Mar 21; cited 2020 May 28]. Available from: https://www.imlindia.com/corona-advisory/pdf/ Corona_Advisory_IML-21Mar2020.pdf.

8. THE DISASTER MANAGEMENT ACT, 2005.

9. THE CONSTITUTION OF INDIA, 1950. Part III.

10. THE CONSTITUTION OF INDIA, 1950, Art. 21.

11. IndiaLegal [Internet] Status of human rights in the age of COVID-19. [updated 2020 May 6; cited 2020 May 28] Available at, https://www. indialegallive.com/special-story/status-of-human-rights-in-the-ageof-covid-19-98488.

12. THE EPIDEMIC DISEASES (AMENDMENT) ORDINANCE, Govt. of India, Ministry of Law and Justice, CG-DL-E-22042020-219108 (2020 Apr 22).

13. THE CONSTITUTION OF INDIA, 1950, Art. 19(1).

14. Arora P, Can doctors be forced to work in epidemic. [video on the internet]. 2020 May 6. Available from: https://www.youtube.com/ watch?v=_KXr35R_-F8.

15. Nandimath OV, Arpitha HC. Medical professional and patientThe Legal relationship. Bengaluru: National Law School of India University; 2017. Module 1, The Medical Profession in India; pp. 5-11.

16. American Medical Association [Internet]. AMA Code of Medical Ethics: Guidance in a pandemic [updated 2020 Apr 14; cited 2020 May 28]. Available from: https://www.ama-assn.org/delivering-care/ethics/ ama-code-medical-ethics-guidance-pandemic.

17. Mehta Y, Chaudhry D, Abraham OC, Chacko J, Divatia J, Jagiasi B, et al. Critical care for COVID-19 affected patients: position statement of the Indian Society of Critical Care Medicine. Indian J Crit Care Med 2020;24(4):222-241. DOI: 10.5005/jp-journals-10071-23395.

18. Mathur R. ICMR consensus guidelines on 'Do not attempt resuscitation'. Indian J Med Res 2020;151(4):303-310. DOI: 10.4103/ ijmr.IJMR_395_20.

19. Telemedicine Practice Guidelines - Enabling Registered Medical Practitioners to provide Healthcare Using Telemedicine. Board of Governers in supersession of the Medical Council of India (in Partnership with NITI Aayog). [updated 2020 Mar 25] Available from: https://www.mohfw.gov.in/pdf/Telemedicine.pdf.

20. Vanderbilt University Medical center [Internet]. Coronavirus (COVID19) Information for Employees And Patients; [cited 2020 May 31]; Available form: https://www.vumc.org/coronavirus/updatedstandard-operating-procedure-obtaining-procedural-informedconsent-during-covid-19-pandemic. 